\title{
Alkali-silica reaction in plain and fibre concretes in field conditions
}

\author{
Graciela Giaccio - María Celeste Torrijos · Carlos Milanesi - Raúl Zerbino $\mathbb{D}$
}

Received: 22 August 2018/ Accepted: 5 March 2019

(C) RILEM 2019

\begin{abstract}
This paper presents an experimental study on the effects of alkali-silica reaction (ASR) in concrete blocks placed outdoors, exposed to weather conditions. To promote different reaction kinetics and damage levels, the size of the reactive aggregates, the alkali content and incorporation of different fibre types (steel, polymer) were the variables considered. Expansions, crack patterns and air permeability were monitored for more than 3 years. In addition, standard expansion, compression and flexion tests were performed. The volume of concrete involved in ASR enhances the development of expansions and cracking; in the blocks different expansions were measured in vertical or horizontal directions and important
\end{abstract}

G. Giaccio

CIC, Commission of Scientific Research, Department of Civil Engineering, La Plata National University, La Plata, Argentina

M. C. Torrijos · R. Zerbino

CONICET, National Council of Scientific and

Technological Research, Department of Civil

Engineering, La Plata National University, La Plata,

Argentina

C. Milanesi

Cementos Avellaneda S.A., Defensa 113 Piso 6,

C1065AAA CABA, Argentina

G. Giaccio · M. C. Torrijos · R. Zerbino $(\bowtie)$

LEMIT, Commission of Scientific Research, Av. 52,

Hipódromo, B1900AYB La Plata, Argentina

e-mail: zerbino@ing.unlp.edu.ar cracks were observed. While the prisms expansions were attenuated after the first 12 months, in the blocks the damage by ASR continues growing for more than 3 years. Although the incorporation of macrofibers does not inhibit the development of ASR, it led to benefits such as reduction in cracking and deformations.

Keywords Alkali-aggregate reaction - Concrete . Degradation · Fibre reinforcement $\cdot$ Mechanical properties $\cdot$ Microcracking
Abbreviations
ASR Alkali-silica reaction
CMOD Crack mouth opening displacement
E Modulus of elasticity
FRC Fibre reinforced concrete
$f_{\mathrm{c}} \quad$ Cylinder compressive concrete strength
$f_{\mathrm{L}} \quad$ Limit of proportionality
$f_{\mathrm{R} 1} \quad$ Residual flexural tensile strength corresponding to $\mathrm{CMOD}=0.5 \mathrm{~mm}$
$f_{\mathrm{R} 3} \quad$ Residual flexural tensile strength corresponding to $\mathrm{CMOD}=2.5 \mathrm{~mm}$

\section{Introduction}

The study of alkali-silica reaction (ASR) has great interest around the world as it is one of the important 
concrete pathologies that can affect diverse types of structures. As it is well known, ASR is a chemical reaction between some elements from the concrete pore solution (mainly $\mathrm{OH}^{-}, \mathrm{Na}^{+}, \mathrm{K}^{+}, \mathrm{Ca}^{2+}$ ) and certain siliceous minerals (opal, chalcedony, volcanic glass, strained quartz, micro-crystalline quartz) present in some aggregates. Under certain conditions of humidity and temperature, the reaction products (siliceous gel) may absorb water and cause deleterious expansion and cracking of concrete [1]. The development of expansions can promote operational problems due to the displacement of the structural elements. In addition, the appearance of cracks enhances the beginning of new mechanisms of deterioration like the corrosion of steel bars or freezing and thawing, which affect concrete mechanical behaviour [2]. The study of ASR is also an important issue for Argentina, a country with a large geographic extension and, consequently, a huge variety of potentially reactive aggregates; a significant number of structures in service affected by ASR have been observed for over more than 50 years $[3,4]$.

Recent literature shows great interest in the study of ASR. Different subjects related to products and kinetic of the reaction considering the influence of salts [5], powders to promote [6] or inhibit ASR [7], the effects of polymer action [8] were studied. There are also many works that use new NDT methodologies for following ASR [9-13], establish criteria for the characterization and assessment of potentially reactive aggregates [14], or improve accelerated tests, particularly the impact of alkali leaching on scale effects affecting expansion tests [15]. Recently, Wallau et al. [16] showed that the use of automated expansion measuring can contribute to improving validity of ASR-testing by excluding additional causes of expansion, as cooling-heating cycles, associated to manual measurements.

The residual mechanical properties of concrete affected by ASR have been studied by numerous researchers $[17,18]$; most of whom agree that the tensile strength and the modulus of elasticity are the most affected parameters, while the compressive strength is less modified. The damage induced by ASR modifies the shape of the load deformation curves; it was verified that concrete failure mechanism is altered both in bending and in compression. As the expansion increases the mechanical properties decrease. Nevertheless, these changes depend on the mineralogy of the rock, the size of the reactive aggregates and the kinetic of the reaction, among other variables [18]. Researches on the response of ASR damaged concretes under multiaxial loads [19] or the relationship between ASR and the compressive strength [20] have been recently performed.

The influence of bars in conventional reinforced concrete or in prestressed elements affected by ASR has been recognized for many years [21-23]. However, very few studies were made on Fibre Reinforced Concrete (FRC) elements to evaluate the potential contribution of different fibres for mitigating the degradation process and their effects on the mechanical and transport residual properties [24-26]. Most of these studies were performed with accelerated and very aggressive conditions as well as artificial reactive aggregates to promote the ASR.

Lindgard et al. [27] highlighted the need of further research in FRC as their physical (e.g., permeability) and mechanical (e.g., strength, toughness) properties might differ from ordinary concrete. A previous research was performed on FRC with natural reactive aggregates to evaluate if different types of fibres can change the rate or the total expansions produced by the ASR [28]. The incorporation of steel or synthetic macrofibres decreased the cracks width and density, also a reduction in the coefficient of air permeability was found, having the steel fibres the best performance. Fibre incorporation had no incidence in the compressive behaviour. In bending, although the peak load decreases, FRC preserved their original residual loading capacity, even though in the case of a severe ASR damage.

The search for a universal testing method that can reproduce the real behaviour of concrete in service has been the subject of study of many researchers [29]. The need to obtain relatively fast results in accordance with project schedules, leads to the use of accelerated methods that reduce the reliability of the results (mortar mixtures, small volume specimens, high temperature, high alkalinity, etc.). In the traditional concrete prism test (ASTM 1293) [29] the curing temperature is moderate $\left(38{ }^{\circ} \mathrm{C}\right)$, the particle size distribution is not significantly modified (no crushing) and the volume of the prism is larger than in the case of mortar bar test (ASTM 1260) [30]. However, one limitation that can be attributed to this method is the alkali leaching [27, 31] that makes difficult the determination of the content of alkali below which 
there is no expansion. A fundamental assumption made in concrete prism testing is that there is a relation between the free expansion of the prisms and the damaging effect of ASR. However, prism expansion does not solely depend on the reaction extent but also on other mechanisms. Nevertheless, the time dependent prism expansion proved to be linked to the damaging effect of ASR, so that the test method is well established for assessing susceptibility of concrete to ASR. Many ASR-modelling approaches infer a timedependent reaction extent from concrete prism tests [16].

Nowadays, there is a great interest in the study of the behaviour of concrete blocks on a larger scale as laboratory results may differ from expansion measured in field cases, mainly due to differences in dimensions, mechanical loads and stress development induced by ASR [32-36]. Concrete block test allows validating laboratory methods and evaluating the ASR mitigation strategies. In addition, although in the prototypes the effects of ASR may become evident after many years, they more accurately reproduce the effects of the ambient temperature fluctuation and reduce the leaching produced in the laboratory specimens. This work presents the results of an experimental research that studies the development of ASR on plain and fibre concrete blocks exposed to the weather conditions during more than 3 years.

\section{Experimental}

The study was performed on concrete blocks incorporating a highly reactive aggregate placed outdoors. In this way the development and effects of ASR were analysed under the regional environmental conditions at a more realistic scale. The size of the reactive aggregates, the incorporation of different types of fibres and the content of alkalis were the variables considered. When coarse reactive aggregates are used, a greater localization of cracks at the interfaces is expected; while with fine reactive aggregates, there is a more diffuse and generalized ASR with lower pressures and possible differences in the reaction kinetics. The fibres cannot inhibit the ASR, however they can restrain the crack openings and then the water movement inside concrete and these effects may be different according to the type of fibre. Finally, low and high alkalis contents were adopted in order to promote different levels and rates of ASR.

Eight concrete blocks of $0.70 \times 0.40 \times 0.40 \mathrm{~m}$ were cast; they were covered with wet clothes during 7 days and then placed outdoors. The meteorological conditions recorded during the testing period of $\mathrm{La}$ Plata city region were: annual mean temperature $17{ }^{\circ} \mathrm{C}$ (ranging between 9 and $25^{\circ} \mathrm{C}$ ), annual mean relative humidity $78 \%$ (ranging between 64 and 85\%) and annual total rainfall $1150 \mathrm{~mm}$ (ranging between 900 and $1500 \mathrm{~mm}$ ). It is expected that alkalis in concrete leach along the time, mainly depending on the crack development; this fact represents a particular difference when compared to standard prisms. However, as these are relatively large blocks, stored outside, it can be considered that little leaching will occur. On the block surfaces, the linear deformations and air permeability were measured. A crack pattern (size and distribution of cracks) survey was also periodically performed to analyse the progress of the reaction and the consequent damage. Figure 1 presents a view of the concrete blocks location and the scheme of the strain measurements.

Standard cylinders $(100 \times 200 \mathrm{~mm})$ and prisms $(75 \times 105 \times 430 \mathrm{~mm})$ were also cast with each concrete for the evaluation of the physical and mechanical properties. The linear expansion over time, the compressive strength, the modulus of elasticity and the behaviour under flexural loads at 28 and 365 days were measured. The laboratory specimens were compacted by external vibration and kept protected after casting to avoid water evaporation. After $24 \mathrm{~h}$ they were wrapped with a cotton sheet and placed inside plastic bags, including $5 \mathrm{ml}$ of water. These bags were stored in a moist room $\left(20 \pm 2{ }^{\circ} \mathrm{C}\right.$, relative humidity $\left.>95 \%\right)$ until testing. It is interesting to mention that recent research has shown that wrapping prisms with cotton sheet will increase the alkali leaching [37].

\subsection{Materials and mixture proportions}

Two series of concretes incorporating Coarse (C) or Fine $(F)$ highly reactive aggregates were studied. The reactive rock was a quartzitic sandstone $(\mathrm{Q})$, with strained quartz grains (some with undulatory extinction greater than $20^{\circ}$ ) surrounded by a matrix constituted by chalcedony and opal among others. Aggregate expansions measured according to ASTM 
Fig. 1 View of the concrete blocks and scheme of strain measurements
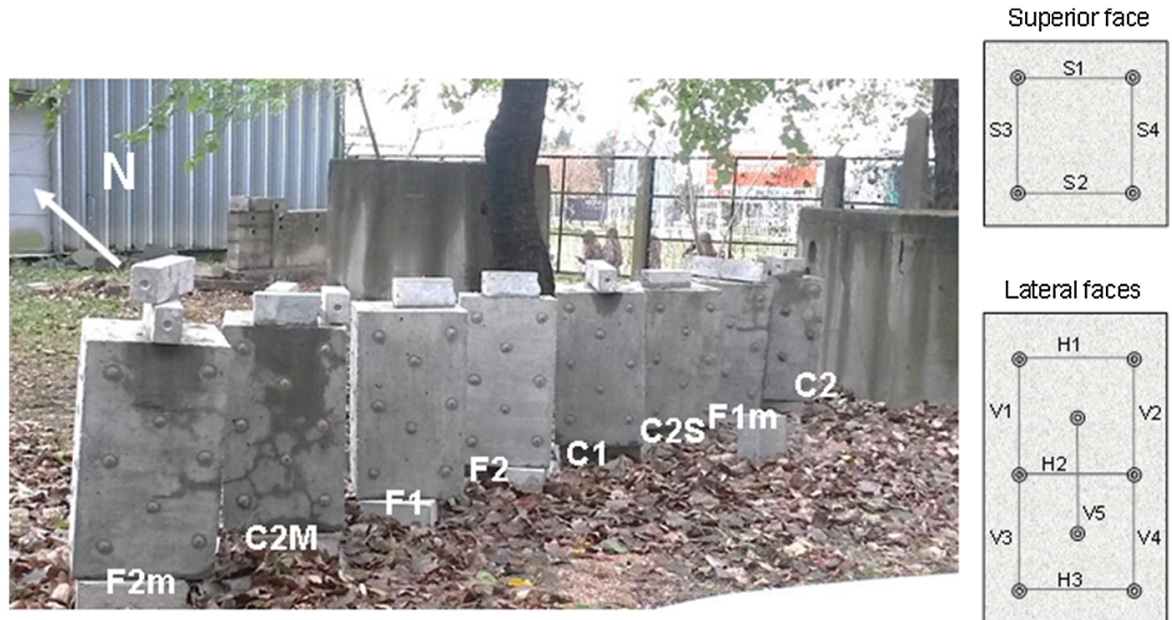

Lateral faces

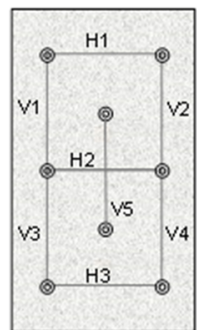

C1260 [30] at 16 days were $0.240 \%$. Expansion tests performed at $38{ }^{\circ} \mathrm{C}$, incorporating this rock as coarse aggregate, following the general guidelines of ASTM C1293 [29], showed that the expansions at 52 weeks were equal to $0.065 \%$. When the coarse aggregate was replaced by $60 \%$ of a non-reactive aggregate, the expansion was $0.142 \%$, showing that this aggregate has a pessimum [27].

Concretes with similar mixture proportions (water/ cement ratio $=0.42$, cement content $=380 \mathrm{~kg} / \mathrm{m}^{3}$ ) and different alkali contents and fibre types were prepared. In Series C, $40 \%$ of Q crushed stone $(19 \mathrm{~mm}$ maximum size) combined with $60 \%$ of $19 \mathrm{~mm}$ granitic crushed stone (non-reactive) was incorporated as the coarse aggregate, while the fine aggregate was $100 \%$ non-reactive natural siliceous sand (fineness modulus 2.07). In Series F, the reactive aggregate $\mathrm{Q}$ was crushed up to a sand size (fineness modulus 2.00) and incorporated as $25 \%$ of the fine aggregate with the other $75 \%$ coming from the non-reactive natural siliceous sand, while the coarse aggregate was the non-reactive granitic crushed stone. The coarse aggregate/sand ratio remains equal to 1.12 in weight.

All concretes were prepared with Ordinary Portland cement $\left(\mathrm{Na}_{2} \mathrm{O}_{\text {eq }}=0.73 \%\right.$, Blaine specific surface $325 \mathrm{~m}^{2} / \mathrm{kg}$, 28-days compressive strength $53.0 \mathrm{MPa}$ ) and the total alkali content of concretes supplied by the cement was equal to $2.8 \mathrm{~kg} / \mathrm{m}^{3}$. To enhance ASR and increase the damage level, in five concretes the total alkali content was increased up to $4 \mathrm{~kg} / \mathrm{m}^{3}$ by adding $\mathrm{NaOH}$ to the mixing water. Concretes with the lower alkali content were identified by $\# 1$ and those with the higher content by \#2. In addition to plain concrete mixtures, different types of fibres were incorporated in both Series. In Series C, low carbon steel fibres (S: hooked-end, $50 \mathrm{~mm}$ length, $1 \mathrm{~mm}$ diameter, tensile strength $>1100 \mathrm{MPa}$, elongation $<4 \%$ ) and synthetic macrofibres (M: modified olefin fibres with embossed surface, $60 \mathrm{~mm}$ length and $0.62 \mathrm{~mm}$ diameter, $640 \mathrm{MPa}$ tensile strength, modulus of elasticity of $10 \mathrm{GPa}$ ) were used. In Series F, synthetic microfibres (m: multifilament $12 \mathrm{~mm}$ length polypropylene fibres) were included.

\subsection{Testing methods}

\subsubsection{Linear expansions on concrete blocks}

Stainless steel reference points were fixed (using an epoxy adhesive after cleaning the surface carefully) on the top and lateral surfaces to perform the strain measurements. Four reference lengths were defined on the superior face of each block ( $S 1$ to $S 4$ ), and three horizontal measures $(H 1$ to $H 3)$ and five vertical ones (V1 to V5) on each lateral face (see Fig. 1). A mechanical deformation device (precision $=0.00254 \mathrm{~mm}$ ) was used. The measurements were done periodically, including summer and winter, avoiding measurements after rainy days.

\subsubsection{Linear expansions on laboratory specimens}

Linear expansions on $75 \times 105 \times 430 \mathrm{~mm}$ prisms stored at $20{ }^{\circ} \mathrm{C}$ were measured as a way to evaluate the 
ASR process. A mechanical length comparator with a precision of $0.00254 \mathrm{~mm}$ was used and the expansions were recorded for up to 1 year. A particular difference between the used Argentinian Standard IRAM 1700 [38] and the corresponding ASTM C1293 Standard [29], is that in the former the prisms are covered with a cotton sheet and placed inside plastic bags, including $5 \mathrm{ml}$ of water.

\subsubsection{Flexural strength and toughness properties in bending}

Prisms of $75 \times 105 \times 430 \mathrm{~mm}$, the same size used to measure linear expansions, were also cast to evaluate the mechanical properties at 28 and 365 days. Three point loading flexural tests on notched specimens were carried out following the general guidelines of EN 14651 Standard [39]. The first-peak strength $\left(f_{\mathrm{L}}\right)$ and the residual flexural strengths at $0.5 \mathrm{~mm}\left(f_{\mathrm{R} 1}\right)$ and at $2.5 \mathrm{~mm}\left(f_{\mathrm{R} 3}\right)$ of crack mouth opening displacement (CMOD) were obtained as results. The first-peak strength $\left(f_{\mathrm{L}}\right)$, or Limit of Proportionality, represents the flexural strength of the plain concrete while the residual flexural strength represents the post cracking capacity of FRC. Tests were performed in a servohydraulic testing system through crack width control, using a clip type extensometer. The use of this method with a closed loop control system leads to evaluate not only the residual properties of fibre concretes but also to compare the postpeak behaviour of plain concretes.

\subsubsection{Compressive strength and modulus of elasticity}

Cylinders of $100 \times 200 \mathrm{~mm}$ were cast to characterize concrete properties in compression at 28 days. Loading-unloading cycles up to $40 \%$ of the maximum stress were applied to determine the modulus of elasticity, and then the load was increased monotonically up to failure.

\subsubsection{Crack pattern}

The surfaces of the four lateral sides of the blocks were carefully examined periodically in order to perform a crack pattern survey. Once the cracks were seen, each face was covered with a transparent film and the visible surface cracks were marked. An imageprocessing software measured the crack lengths [28]. Also, the maximum crack width was measured with a magnifying glass on each face. The glass has a precision equal to $0.05 \mathrm{~mm}$.

\subsubsection{Air permeability}

To assess the damage level of concrete blocks, the air permeability was measured periodically with a Torrent equipment; this apparatus, that evaluates the cover concrete, has a two-chamber vacuum cell and a regulator that balances the pressure in the inner (measuring) chamber and in the outer chamber $[40,41]$. As the air permeability is affected by moisture conditions, the measurements were done at the same time and under the same environmental conditions avoiding testing after rainy days. Measurements were always made at the upper zone of the north-west $(\mathrm{NW})$ face of each specimen.

\section{Results and analysis}

\subsection{Concrete mechanical properties}

Table 1 presents the identification of the eight studied concretes and, as a reference, their mechanical properties measured on standard specimens. All concretes had similar strength levels with mean values for compressive strength and modulus of elasticity of 34.3 $\mathrm{MPa}$ and 41.5 GPa for Series $\mathrm{C}$, and $37.1 \mathrm{MPa}$ and $39.7 \mathrm{GPa}$ for Series F, respectively.

Table 1 also presents the results from three point loading flexural tests on notched specimens, at 28 days and at 1 year. In Series C, it appears that at 1 year the most damaged concrete $(\mathrm{C} 2)$ shows a great decrease in the bending strength and a significant increase in the residual stress $f_{\mathrm{R} 1}$ (increase in softening branch of the curve) which indicate an extensive crack formation in the concrete. This effect does not appear in $\mathrm{C} 1$ where both the maximum load and the post peak behaviour are similar when 28 and 365 days tests are compared, indicating that no significant damage or cracking took place after 1 year. When FRC with high alkali contents are considered, again there are decreases in the first peak loads; however, the residual strength capacity does not significantly decrease between 28 days and 1 year. Thus, although ASR cracks are present, the residual capacity is not affected. These results agree with previous works on damaged FRC [28] where more information about the 
Table 1 Concrete properties

\begin{tabular}{|c|c|c|c|c|c|c|c|c|}
\hline Concrete & $\mathrm{C} 1$ & $\mathrm{C} 2$ & $\mathrm{C} 2 \mathrm{~S}$ & $\mathrm{C} 2 \mathrm{M}$ & $\mathrm{F} 1$ & $\mathrm{~F} 1 \mathrm{~m}$ & $\mathrm{~F} 2$ & $\mathrm{~F} 2 \mathrm{~m}$ \\
\hline Reactive aggregate & Coarse & & & & Fine & & & \\
\hline Total alkalis $\left(\mathrm{kg} / \mathrm{m}^{3}\right)$ & 2.8 & 4 & 4 & 4 & 2.8 & 2.8 & 4 & 4 \\
\hline Fibres type & None & None & $\mathrm{S}$ & $\mathrm{M}$ & None & $\mathrm{m}$ & None & M \\
\hline Fibres content $\left(\mathrm{kg} / \mathrm{m}^{3}\right)$ & & & 40 & 3 & & 1 & & 1 \\
\hline Slump (mm) & 90 & 70 & 90 & 90 & 75 & 25 & 90 & 35 \\
\hline$f_{\mathrm{c}}(\mathrm{MPa}) 28$ days & 34.2 & 32.4 & 33.0 & 37.6 & 37.6 & 39.5 & 33.5 & 37.8 \\
\hline$E(\mathrm{GPa}) 28$ days & 44.3 & 41.1 & 39.3 & 41.5 & 41.8 & 39.8 & 40.3 & 36.9 \\
\hline$f_{\mathrm{L}}(\mathrm{MPa}) 28$ days & 5.6 & 5.7 & 6.4 & 5.1 & 4.5 & 4.3 & 3.8 & 4.0 \\
\hline$f_{\mathrm{L}}(\mathrm{MPa}) 365$ days & 5.2 & 3.3 & 3.9 & 3.2 & 4.6 & 4.7 & 4.6 & 4.7 \\
\hline$f_{\mathrm{R}, 1}(\mathrm{MPa}) 28$ days & 1.0 & 0.9 & 4.9 & 2.3 & 1.5 & 1.3 & 1.5 & 1.4 \\
\hline$f_{\mathrm{R}, 1}(\mathrm{MPa}) 365$ days & 1.2 & 2.0 & 4.7 & 2.6 & 1.9 & 1.7 & 1.9 & 1.9 \\
\hline$f_{\mathrm{R}, 3}(\mathrm{MPa}) 28$ days & 0.1 & 0.1 & 4.0 & 1.6 & 0.1 & 0.4 & 0.4 & 0.3 \\
\hline$f_{\mathrm{R}, 3}(\mathrm{MPa}) 365$ days & 0.2 & 0.3 & 3.8 & 1.7 & 0.3 & 0.4 & 0.3 & 0.6 \\
\hline
\end{tabular}

relationship between the variation in mechanical properties and the expansion measured on similar prisms can be found. The lower sensitivity of the fibre bond strength to the presence of cracking, compared with the matrix strength, can explain this behaviour.

Regarding Series F, it can be seen that the most damaged concrete (F2) shows an increase in the peak load and in the residual capacity at 1 year. In this case, the smaller differences between 28 days and 1 year can be explained considering that the ASR mechanism involves crack initiation and propagation from fine aggregates (the effects on the coarse aggregate interfaces are minimum), the amount of reactive material is smaller ( $25 \%$ of sand), and, as it will be discussed later, the measured expansions are smaller. As expected, microfibres only have a minor effect on the residual behaviour when compared to plain concretes. It can be mentioned that no significant effects of microfibres associated with the control of ASR damage can be inferred from the load-CMOD curves in bending. This was expected as only minimum differences were found in the expansion tests. However, it can be emphasized that the evolution of expansions and cracks should be very different in the case of the blocks, as it will be described next.

\subsection{Linear deformations on concrete blocks and laboratory prisms}

The evolution of deformations measured on blocks and laboratory prisms can be very different. The volume of concrete affects the availability of water and imposes restrictions for expansions which causes the initiation and propagation of cracks in specific orientations. At the same time, the faces of the blocks had different orientations and experienced sun irradiation. In addition to the expansion caused by the ASR, the blocks may also undergo expansions and/or shrinkage produced by changes in humidity and temperature from being outdoors (as no corrections for outside temperature were done, the results show the variation of the total deformation). But, more significant is that the alkalis leaching capacity should be very different than in the case of small specimens and also varies along time depending on the crack size. As the cracks develop, the water movement (wetting and drying) increases.

Figure 2 compares the individual linear expansions measured on one lateral face of the blocks $\mathrm{C} 1, \mathrm{C} 2$ (one of the most damaged) and $\mathrm{C} 2 \mathrm{~S}$. The values of vertical $(V)$ and horizontal $(H)$ deformations in the case of the sides of the blocks are also shown. In $\mathrm{C} 1$, which incorporates the lower alkalis content $\left(2.8 \mathrm{~kg} / \mathrm{m}^{3}\right.$ $\mathrm{NaOH}_{\text {eq }}$ ), no cracks were found and the deformations are very small as well as the results' variability. In blocks $\mathrm{C} 2$ and $\mathrm{C} 2 \mathrm{~S}$ the expansions and their variability are higher; however, all measurements present the same tendency. When the different faces (and consequently, different orientations: NE, NW, SE, SW) were compared, a clear differentiation between their deformations were not found, and then the mean values were considered for the analysis. In $\mathrm{C} 2 \mathrm{~S}$, the expansions and their variability are lower than in $\mathrm{C} 2$. It can be inferred that the presence of fibres leads to some 

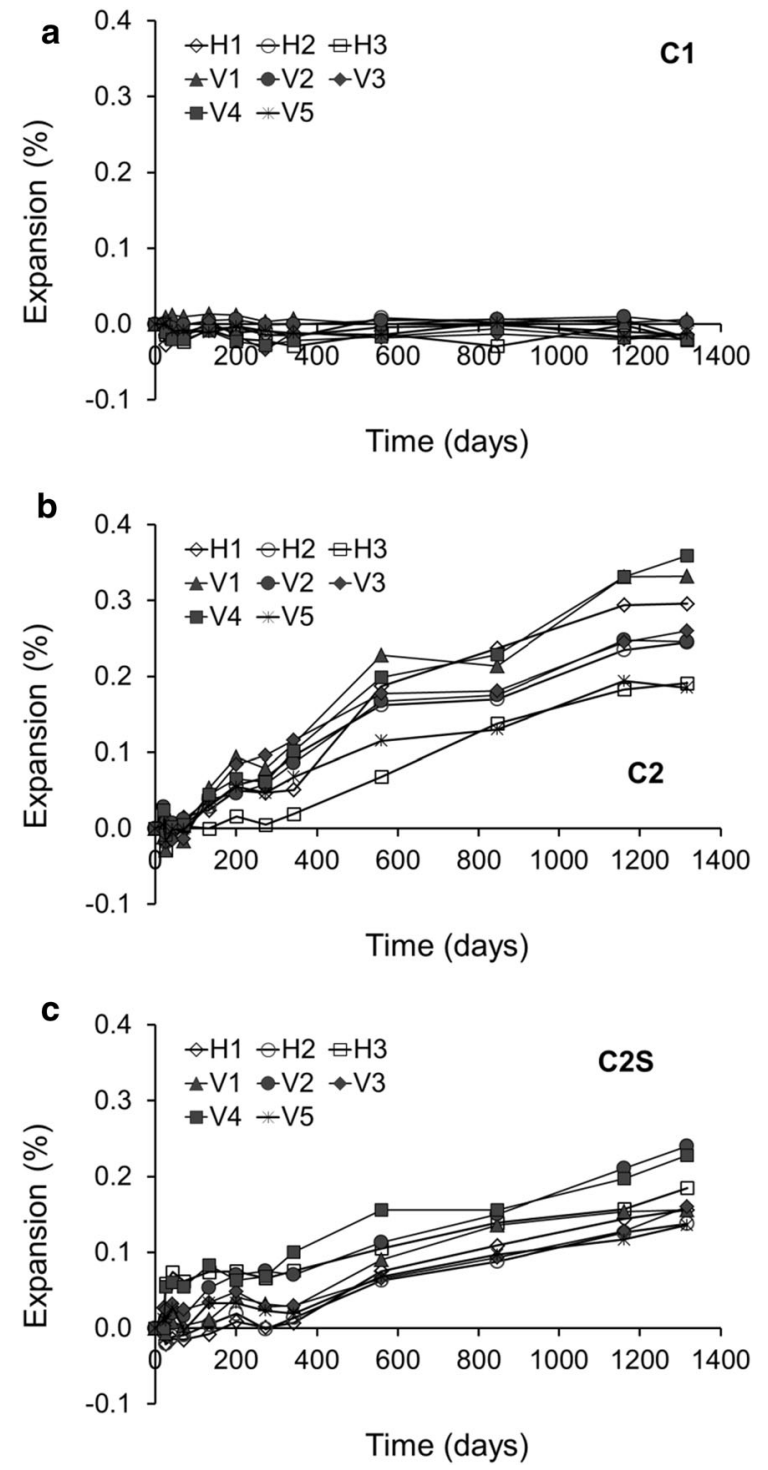

Fig. 2 Examples of individual linear expansion measurements

control of the expansions and also to a more uniform distribution of the deformations.

Figure 3 compares the mean values of the vertical $(V)$, horizontal $(H)$ and top surface $(S)$ expansions of Series $C$ concretes. It can be seen that $V$ expansions are higher than $H$ and $S$, which is in accordance with other authors' observations [23, 42-44]. This anisotropic behaviour is related with the greater horizontal cracking, which will be justified and discussed later. The greatest differences correspond to the most damaged concrete $(\mathrm{C} 2)$. Note that differences between $V, H$ and $S$ expansions vary in the case of FRC. Great scattering can be seen on the measurements especially as expansion increases. This can be justified considering that when a crack appears a sudden increment in deformation takes place if the base of measurement includes the crack while a decrease in expansion appears if the crack formation is at the neighbour zone outside the measurement line. However, general tendencies are very clear. It must be mentioned that a similar behaviour was observed in the case of Series $\mathrm{F}$; nevertheless the differences between the different orientations $(V, H, S)$ significantly decrease. This is attributed to the small size and content of the reactive aggregate (25\% of sand) that promotes more distributed reaction effects (cracking).

Figure 4 summarizes the mean linear expansions ( $V$ and $H$ ) measured on each block of Series $C$ and F. For comparison, the linear expansions measured on prisms, stored in closed bags in saturated conditions at $20{ }^{\circ} \mathrm{C}$, for up to 1 year are also shown (each curve corresponds to the mean of four prisms).

When analysing the linear expansions measured on Series $\mathrm{C}$ prisms, it can be seen that concrete $\mathrm{C} 1$ $\left(\mathrm{Na}_{2} \mathrm{O}_{\text {eq }}<3 \mathrm{~kg} / \mathrm{m}^{3}\right)$ does not present significant expansion. On the contrary, C2 appears as a very reactive concrete, achieving an expansion greater than $0.2 \%$. In $\mathrm{C} 2$ there is an induction period of nearly 2 months, and after that, the expansion rate is very high. When fibres are incorporated, the induction period seems to be longer (near 3 months). It is possible that the fibres control the initial expansions to some extent. After this period, the expansion rate increases, but it is quite lower than in $\mathrm{C} 2$, achieving maximum expansions at 1 year on the order of $60 \%$ of C2. It must be mentioned that in the standard test performed at $38{ }^{\circ} \mathrm{C}[29,38]$, the expansion limit at 1 year is $0.04 \%$; $\mathrm{C} 2, \mathrm{C} 2 \mathrm{M}$ and $\mathrm{C} 2 \mathrm{~S}$ exceeded this value after only a few months.

The linear expansions in Series F are clearly lower than in Series C. Nevertheless, the expansion development starts earlier. The incorporation of microfibres does not modify concrete expansions substantially; however, in the case of F2m they are slightly lower than in F2. Expansion in F1 (with low alkali content) is lower than in F2, but it clearly exceeds the values measured in $\mathrm{C} 1$, indicating that some ASR is present.

Analysing the mean linear expansions measured on the blocks it can be seen that in $\mathrm{C} 1$ there is no expansion, $\mathrm{C} 2$ has the maximum expansion, and $\mathrm{C} 2 \mathrm{~S}$ and $\mathrm{C} 2 \mathrm{M}$ show an intermediate behaviour with $\mathrm{C} 2 \mathrm{~S}$ 
Fig. 3 Linear expansion measurements on different orientations
Fig. 4 Linear expansions measured on prisms and concrete blocks
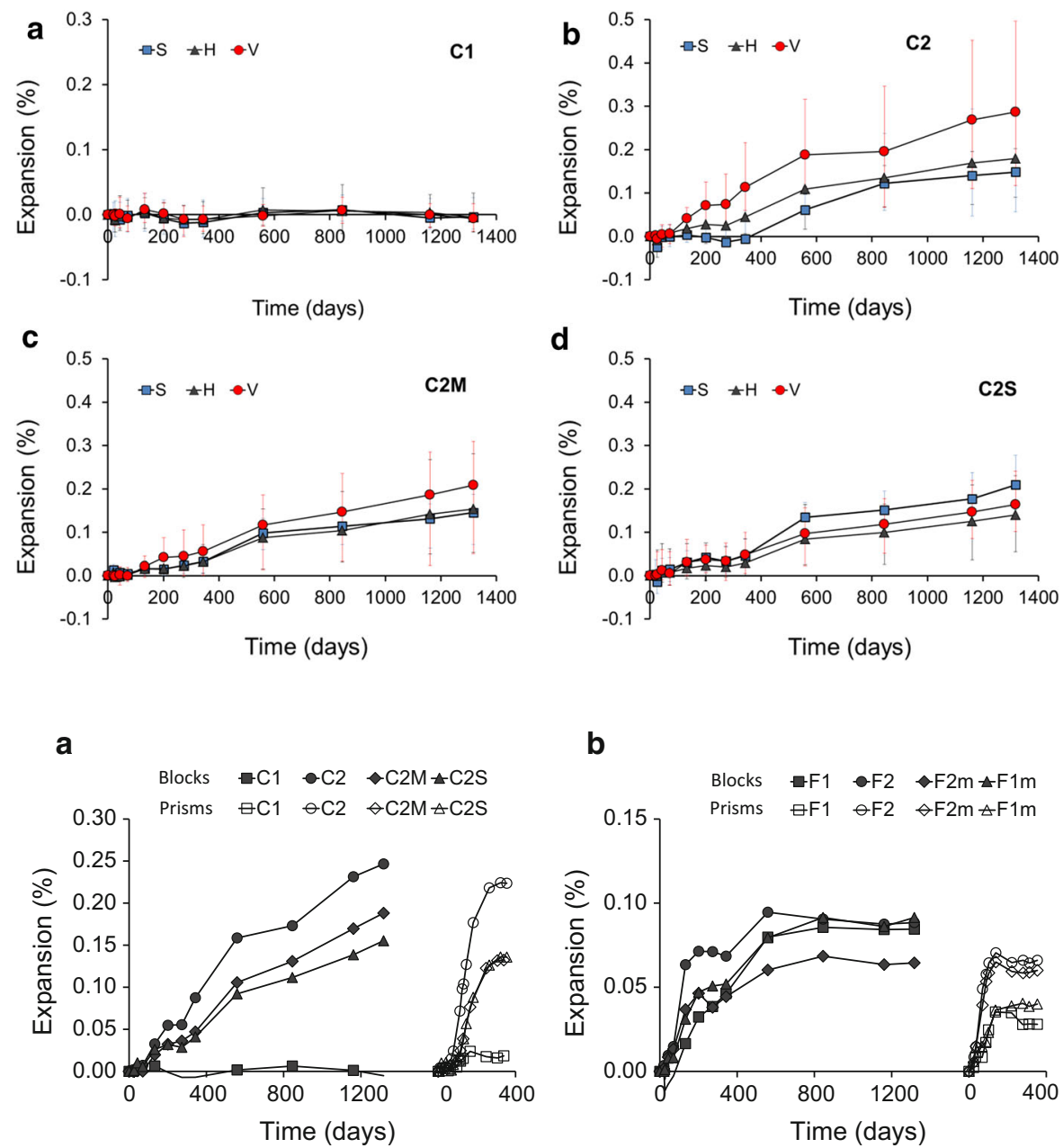

being somewhat lower. Note that the deformations did not stabilize and continue increasing over time (nearly 4 years). On the contrary, in the laboratory prisms, the expansions become stable at earlier ages. Although the small specimens are maintained inside plastic bags covered with humid cotton sheets, some alkali leaching takes place; in the case of the concrete blocks the greater volume makes more difficult the leaching of alkalis and to maintain the internal humidity necessary for ASR [35]. Later, as cracks appear concrete transport properties change increasing the possibility of leaching. Along the block, the leaching capacity also depends on the proximity to the edges and the weather conditions. This must be taken into account when analysing expansion rates and differences between horizontal and vertical expansions. It can be assumed that the alkalis content is not constant inside the block, and it varies between bulk and cover concrete, zones close or far from the cracks or the edges. In Series $\mathrm{F}$ the expansions are lower than in Series C. Again, at nearly 3 months, the curves show an increase in expansion and then the increments decrease in a significant way. The laboratory prisms present a similar behaviour. In the case of the blocks, after nearly 2 years, concretes with lower alkali content achieved similar expansion values as concrete F2. When this amount of reactive sand was combined with the higher alkali content, the expansion was exhausted in a few months; whereas when combined with less alkali content, the expansion continues slowly through the years. As will be seen in the discussion, the fibres contribute, in some extent, to decrease the expansions. 


\subsection{Crack pattern evolution on concrete blocks}

The crack density survey for each block is presented in Fig. 5. Each value is the average of the densities assessed in the four lateral faces. Two hundred days after the blocks were cast, the cracks started to become visible. In Series C (reactive coarse aggregates), concrete $\mathrm{C} 2$ had the highest crack density from the beginning, with this difference increasing with time. Concretes incorporating steel $(\mathrm{C} 2 \mathrm{~S})$ and polymeric (C2M) fibres had a similar crack density at all ages. At the age of 3 years, concretes $\mathrm{C} 2 \mathrm{~S}$ and $\mathrm{C} 2 \mathrm{M}$ had a crack density almost 50\% lower than $\mathrm{C} 2$. In these three concretes, a marked increase in crack density is observed up to the first year, then, the increment is smaller, especially in the FRCs. In contrast, no cracks were found in C1. In Series F (reactive fine aggregates) the crack density grows markedly until the first year and then starts to stabilize. Cracks were seen in all four blocks of Series F; however, the crack density is lower than that for concretes $\mathrm{C} 2, \mathrm{C} 2 \mathrm{~S}$ or $\mathrm{C} 2 \mathrm{M}$. The lowest value of crack density corresponds to F1m. This behaviour is in accordance with the measured expansions.

When considering the evolution with time of the average maximum crack width it appears that in Series $\mathrm{C}$, the crack width is higher in $\mathrm{C} 2$ and, unlike the crack density, the width continuously grows with time. It seems that in FRCs the increase is slower, mainly after 2 years. In the case of Series F, the increase in the crack width follows a tendency similar to the crack density, it grows until the first year and then it becomes stable. The crack width is also smaller in F concretes than in $\mathrm{C}$ concretes. The greater localization of ASR when coarse aggregates are used leads to higher crack widths.
It must be mentioned that, during the crack survey, it was observed that the first cracks came out from the vertical edges of the concrete blocks. In the first year, most of the cracks were oriented horizontally while with time, as the reaction progressed and the crack density increased, the cracks were distributed more randomly (nevertheless the horizontal direction prevails). It is important to highlight that, although fibre incorporation did not inhibit the ASR, the macrofibres reduced the cracking produced by the reaction.

\subsection{Air permeability}

As a way to make evident the development of ASR damage in the blocks, the air permeability was also measured. As the Torrent permeability is measured on the surfaces of the blocks, surface cracking has an important impact on the results. The aim to include this evaluation was to detect incipient cracking due to ASR; when significant cracking develops the sensitivity of air permeability measurements decline. According to Torrent equipment [40], a concrete with an air coefficient below $0.01 \times 10^{-16} \mathrm{~m}^{2}$ is of very good quality, if the coefficient is between 0.01 and $0.1 \times 10^{-16} \mathrm{~m}^{2}$ it is good, between 0.1 and $1 \times$ $10^{-16} \mathrm{~m}^{2}$ is normal, between 1 and $10 \times 10^{-16} \mathrm{~m}^{2}$ is bad and a concrete with a coefficient higher than $10 \times 10^{-16} \mathrm{~m}^{2}$ can be considered very bad.

Figure 6 shows the evolution of the air permeability over time. Although, as happens with the properties of damaged concrete, there is some variability of results the tendency is clear. It can be seen that since the second year, concretes $\mathrm{C} 2, \mathrm{C} 2 \mathrm{~S}, \mathrm{C} 2 \mathrm{M}$ and $\mathrm{F} 2$ have the highest air coefficients, and can be considered bad or very bad. In general, there is an increase in the coefficients over time. It must be noted that no significant conclusions can be obtained comparing
Fig. 5 Evolution of crack density (left) and maximum crack width (right) on concrete blocks
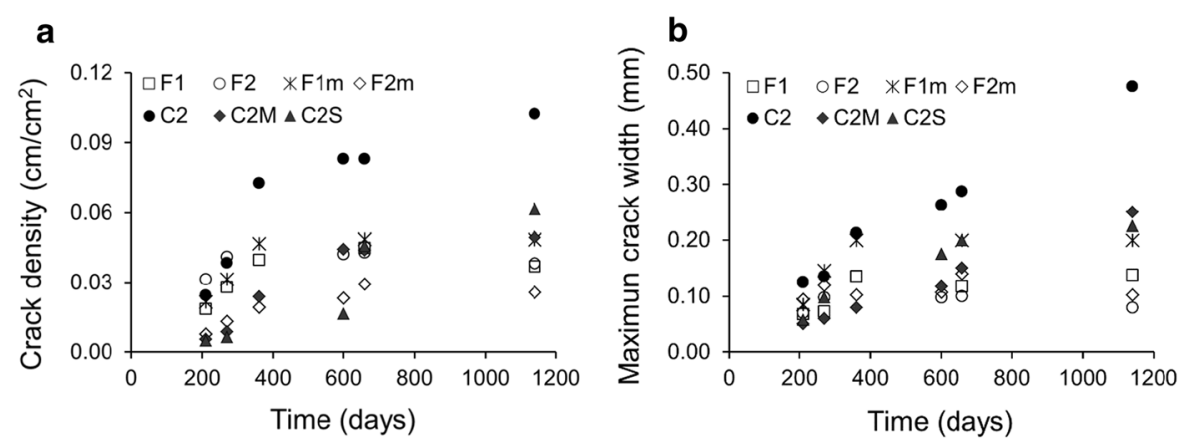


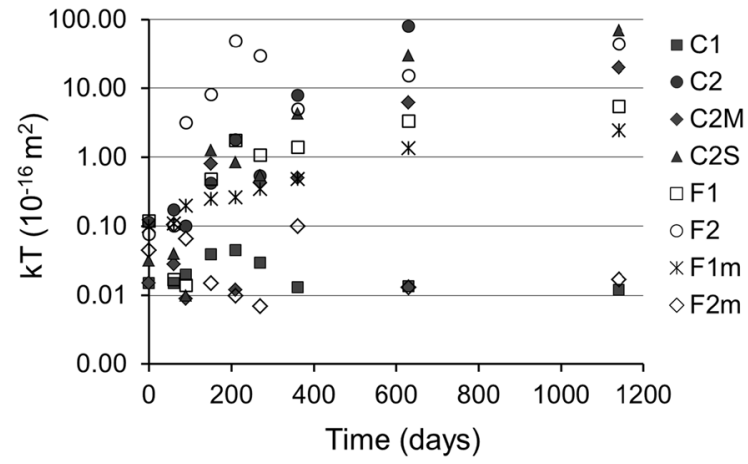

Fig. 6 Evolution of the air permeability with time

concretes that achieved coefficients that correspond to bad or very bad qualities, because these results are due to the presence of significant cracking. Thus, the main contribution of these measurements was the detection of early cracking even before visual observations.

These observations are in accordance with the crack survey (density, maximum widths), but the changes in permeability appeared before visible cracks were detected (possible microcracking).

\section{Discussion}

As it was mentioned, the accelerated methods introduce testing conditions that reduce the reliability of the results when analysing ASR (as small reactive particles, small volume specimens, high temperature, and high alkalinity). An assumption in the concrete prism testing is that there is a relation between the free expansion and the ASR damaging effect; a limitation of the prism test is the possibility of alkali leaching that makes difficult the determination of "alkaline threshold" (alkalis content bellow which no expansions are produced by ASR).

The use of concrete blocks exposed to the environmental conditions of the region enables the discussion of the development of ASR and its effects on concrete properties on a more realistic scale. In this study there were selected many variables in order to promote the development of ASR deleterious processes of different characteristics. The use of fine or coarse reactive aggregates, the content of alkalis as well as the incorporation of different fibres lead to different kinetics of reaction, levels of expansion, crack patterns and mechanical responses.
As expected, the effects of ASR on the concrete blocks differ from those observed on the laboratory prisms [35]. In the blocks it was possible to verify the development of cracks of different size and orientation and, also, differences in the expansion rates. The volume of concrete involved in the case of the blocks enhances the appearance of typical signs of ASR detected in real structures, such as significant cracking.

Among the factors that modify the behaviour of blocks and prisms appears the availability of water for the ASR. Concrete water content changes due to the wetting and drying process as well as to the appearance of cracks. It should be noted that the water content can also vary along the blocks, mainly after the cracks were formed.

In the blocks, the cracks start from the vertical edges and then they propagate in accordance with the geometry of the element, first in a horizontal direction and finally following a more random pattern. At the vertical edges the moisture content may be lower than at the centre of the sides. In these conditions the ASR expansion decreases and drying shrinkage increases, leading to a greater deformation gradient.

The size and orientation of the cracks are very significant regarding the durability of concrete as well as other properties such as stiffness and strength. In addition, the presence of cracks can enhance the development of the ASR.

Greater deformation was found in the direction of filling (vertical), associated to the greater horizontal orientation of the cracks. This behaviour agrees with that observed by other authors [23, 42-45]. It was mentioned that this anisotropic response could be a result of the effects of water accumulation under the aggregates, which causes planes of weakness perpendicular to the direction of casting and also voids near the aggregates that act as reservoirs for the ASR gel [42]. When comparing the expansions of the lower and the upper zones of the blocks, not significant differences were detected; a reference of the variability in the measurements was shown in Fig. 2. The expansions and the crack patterns were similar at the different faces of each block (no effects of orientation or irradiation were found). Although expansion variability increases as expansion increase, tendencies are similar; scattering is mainly due to the effect of crack formation. An example can be seen comparing the results of concretes $\mathrm{C} 1$ and $\mathrm{C} 2$ in Fig. 3. 
In addition, and as it was mentioned, cracks usually grow at the corners of the blocks and then propagates mainly in horizontal direction. The presence of water is obviously essential to increase the amount of ASRproducts [44], and although significant ASR expansions can occur without an external water supply, anisotropic effects can also result from differences in drying and water availability. There were measured ASR expansions near 2.5 times higher when comparing specimens stored in water with sealed ones [43]. In the same paper the vertical expansion measured on cylinders was approximately twice the horizontal expansion measured on prisms. However, there is a threshold below which there is not enough water for the chemical reactions. In this case expansion and ASR-products formation stop but if water comes back ASR can start again. Nevertheless, irregular water supply affects concrete expansion [44].

Regarding the source of ASR damage in the blocks prepared with reactive coarse aggregate (Series C) the cracks are larger and the expansions are greater than in the blocks incorporating reactive sand (series F). This can be attributed to a major localization of the deformations and stresses at the coarse aggregate interfaces. In Series $\mathrm{C}$ concretes with high alkali contents continue expanding after 3 years; at the present expansions are not significant in the case of $\mathrm{C} 1$ (low alkali content). In Series F concretes (reactive sand) an expansion increase was detected after 3 months and the expansion stabilized just before 2 years, indicating that probably most of the available alkali decreased below the threshold required for the progress of the reaction. In Series F at advanced ages all concretes (with low and high alkali contents) show a certain level of expansion (Fig. 4). On the contrary, $\mathrm{C} 1$ showed no expansions for up to 3 years, however, it cannot be discarded that the aggregates will react later as this concrete has an alkali content close to $3 \mathrm{~kg} / \mathrm{m}^{3}$ and the coarse aggregate is highly reactive [46].

Regarding the observed behaviour from the prism tests, it can be mentioned that in Series $C$ the prism test results showed a highly deleterious response for concretes incorporating high alkalis contents, with greater expansions than in the blocks at a same age. In concretes incorporating $25 \%$ of reactive sand (Series F) the prisms expansions at 1 year were slightly lower than those measured in the blocks. It must be emphasized that the observed structural anisotropy was not observed in the case of this prisms.

When comparing the evolution of blocks and laboratory prism expansions, it can be observed that in the small specimens the deformations become stable at earlier ages. These differences can be attributed to different alkali leaching capacity between the small specimens and the concrete blocks and are in accordance with other authors.

Gao et al. [47] explain the combined effect of the aggregate and specimen sizes on ASR expansions, considering the diffusion rate of ionic species into the material porosity. They measured the expansions of mortar bars of different sizes immersed in $\mathrm{NaOH}$ solution, varying the size of reactive aggregates from 0.3 to $2.5 \mathrm{~mm}$, and conclude that for a same aggregate size, small prisms need less time to achieve final expansions while for a same specimen size, the time to reach final expansions decreases as the size of reactive particles decreases. ASR-gels can leach off depending on the distance to specimen borders or cracks and the expansion stops as the pressure in the gels falls. Lindgård [48] presented major details of the effect of specimen sizes on ASR performance testing. The influence of potentially reactive aggregate particle size on ASR has been discussed in recent papers $[49,50]$ confirming that there is a significant effect on the ASR rate as well as on the potential expansion and damage in concrete structures. However, contradictory results were observed in some cases when comparing expansion results from blocks at the outdoor exposure site and laboratory specimens. It was mentioned that the reactive aggregates can show different pessimum particle sizes and that the effects of aggregate particle size on ASR expansion depend not only on the rock composition but also on the exposure conditions.

The cracking level and the deformations measured on the blocks are consistent. From Fig. 5 it can be seen smaller crack sizes in Series F; although differences in $\mathrm{V}$ and $\mathrm{H}$ expansions were also found in this case, there were lower than in the case of Series C. This can be associated with the smaller crack size, the greater dispersion of reactive particles.

Figure 7 shows a photograph of one side of the block C2 (including a detailed zone of the block) and a photograph of a prism of the same concrete that was stored by the block. It can be clearly seen that while there is extensive cracking on the block surface, only few and quite smaller cracks are present in the prism. 


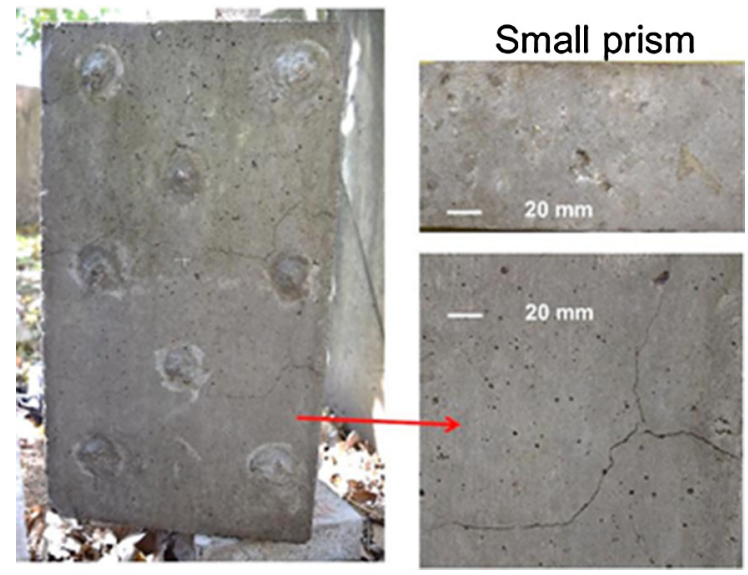

Fig. 7 Concrete C2. Comparison of the surface cracking of the block and the small prism (right-top) at the age of 45 months

As air permeability varies with the moisture conditions the results must be mainly analysed in comparative way between the different blocks. In addition, as it evaluates the cover concrete, the results can be strongly affected by the characteristics of cracks. It must be noted that the Torrent equipment was not develop for highly-damaged concretes. Even taking in mind the limitations of the method previously mentioned, it is very interesting to note that the coefficient of permeability significantly increased in many blocks before 200 days of exposure when no cracks were detected (Fig. 6). The earlier changes in permeability make it possible to infer that there was incipient micro-cracking detected by this method; great variations were seen in $\mathrm{C} 2$ and F2. After 2 years, the permeability coefficients indicated significant cracking in most blocks, with the exception of $\mathrm{C} 1$ where no cracks were seen.

Although there are many references about the development of ASR in conventionally reinforced concrete, significant differences are expected in the case of FRC. While conventional bars are continue, located in specific places and oriented, fibres are discretely and randomly distributed. However, a 2D distribution in horizontal planes is expected in the case of steel and polymer macrofibres. At the same time it must be pointed out that the fibre volume is small, in this case near $0.5 \%$.

Many authors found lower expansions in RC members than in unrestrained pieces of concrete. Restrain can result from applied loads, from the stressing of the reinforcement within the concrete or from adjacent concrete that has not expanded to the same degree [42, 51-53]. Jones and Clark [42] show that the expansion decreases below $40 \%$ of the free expansion as the reinforcement increases over $1 \%$; for $0.5 \%$ of reinforcement the expansion was near $60 \%$ of the free expansion. It was also noted that the rate of expansion of RC did not change significantly with the final expansion as both of them are governed by the microcrack pattern formed at low expansions. Conventional reinforcement also promotes an anisotropic behaviour, there were measured lower expansions along the reinforced direction, and the unrestrained expansions were not the same as free expansions of plain concrete. A study performed on concrete RC beams showed a large decrease of deflections and strains along the longitudinal direction as well as local effects of stirrups [52]. Recent studies on multiaxial reinforced concrete members confirm that ASR expansions are greater in the unreinforced directions and that variation in reinforcement ratios between 0.5 and $1.5 \%$ have minimal influence on the level of restraint provided against expansion [54, 55].

The incorporation of both steel and macrosynthetic fibres (Series C) leads to some control and distribution of deformations, with the maximum deformation, the maximum crack width as well as the crack density being lower than in the case of the plain concrete $\mathrm{C} 2$. As the volume of fibres is usually lower than $0.5 \%$, it can be expected that expansion reductions due to fibre incorporation will not be necessarily significant. However, in these experiences the use of steel and polymeric macrofibres led to reductions in the mean expansion after 2 years of near 35 and $25 \%$ when compared with $\mathrm{C} 2$. It is interesting to note that the higher decreases corresponded to the vertical direction (near 45 vs. $25 \%$ in $\mathrm{C} 2 \mathrm{~S}$, and 30 vs. $20 \%$ in $\mathrm{C} 2 \mathrm{M}$ ).

When comparing $\mathrm{C} 2, \mathrm{C} 2 \mathrm{~S}$ and $\mathrm{C} 2 \mathrm{M}$ (Fig. 3), it can be seen that while similar mean deformations were found on the top $(S)$ of the blocks (between 0.1 and $0.2 \%$ ), differences between vertical $(V)$ and horizontal $(H)$ expansions were higher in $\mathrm{C} 2$. This can be attributed to a greater size and amount of horizontal cracks. Vertical expansions are also greater in $\mathrm{C} 2 \mathrm{M}$ than in $\mathrm{C} 2 \mathrm{~S}$, showing some improvement in crack control capacity for the steel fibres which is in accordance with the expansions measured on prisms [28]. Regarding the high variability of the results, it must be taken in mind that while the expansions strongly increase if a crack propagates through the 
measurement length, when the crack appears outside this length, close to the reference points of measurement, the deformations decrease. However, when considering the mean results the tendencies are very clear.

When polymer microfibres were incorporated (Series F), in only one case a slight decrease in expansion was found. It is important to highlight that macrofibres significantly reduced the cracking produced by the reaction and this can become important when considering the possibility of extra damage produced by the access of aggressive products in concretes. In the case of polymer microfibres the stresses, even using fine reactive aggregates, are high enough so the fibre cannot control crack growth. Finally, it was verified that the bending post-peak (residual) capacity of FRC damaged by ASR is not significantly modified. Both, steel or synthetic macrofibres concretes conserve their original post peak loading capacity even when severe ASR damage has taken place. This can be explained considering that the bond strength is less affected than the matrix strength [56].

\section{Conclusions}

This paper studied the behaviour of plain and fibre reinforced concrete blocks affected by ASR. To promote deleterious processes of different characteristics, the content of alkalis, the size of the reactive aggregates (fine or coarse) and the incorporation of different fibres were the variables considered. Based on the analysis of the expansions, the mechanical properties and the development and characteristics of cracks, it can be concluded that:

- In the concrete blocks important cracks were observed. The volume of concrete involved in the ASR enhances the development of expansions and cracking. The cracks start from the less restricted zones; they initially propagated in the horizontal direction in accordance with the greater expansions parallel to the casting direction (vertical), and finally a more random pattern develops. When a smaller volume of concrete was considered (prism stored next to the block) only a few and quite smaller cracks were present.
- The size of the reactive aggregate modified the kinetic of the reaction and the crack pattern. When concrete had high alkali content and coarse reactive aggregates the expansions and cracks were very important and they continued increasing after 3 years. In the case of lower alkali content, the concrete expansions were negligible and no cracks were detected. When the reactive sand was used, both expansions and cracking were quite smaller. The increase in expansion tended to stabilize at nearly 2 years, indicating that probably some of the factors involved in the ASR had become exhausted. At advanced ages, concretes with low alkali content showed nearly the same expansion as concretes with high alkali content.

- The incorporation of macrofibres, although it cannot inhibit the ASR, leads to some benefits such as a reduction in cracking and some decrease in the expansions. Differences between vertical and horizontal expansions as well as the variability of results were lower in fibre concretes. The deformations and the air permeability measured on the blocks are consistent with the cracking level, but the changes in permeability started earlier, probably detecting incipient micro-cracking. Although the matrix strength decreases, concretes with macrofibres conserve their original post peak loading capacity even when severe ASR damage has taken place.

Acknowledgements Funding from projects National Scientific and Technical Research Council (CONICET) PIP 112-201101-00765 Development and characterization of fibre reinforced concretes for structural applications and PIP 112-201501-00861 Advances in fibre reinforced concretes, La Plata National University UNLP PPID2012 Damage processes in fibre reinforced concretes and UNLP 11/I188 Fibre reinforced concretes and their contribution to the sustainable development, as well as the collaboration of Cementos Avellaneda, Cementos Artigas and Maccaferri are greatly appreciated. The authors specially thank the collaboration of M.E. Bossio, P. Bossio, A. Gerez and D. Falcone in the support of experimental works.

\section{Compliance with ethical standards}

Conflict of interest The authors declare that they have no conflict of interest. 


\section{References}

1. ACI Committee 221 (1998) State-of-the-art report on alkali aggregate reactivity. Report No. ACI 221-1R-98. American Concrete Institute, Farmington Hills

2. Fournier B, Bérubé M-A (2000) Alkali-aggregate reaction in concrete: a review of basic concepts and engineering implications. Can J Civ Eng 27:167-191

3. Fava ASC, Manuele RJ, Colina JF, Cortelezzi CR (1961) Estudios y experiencias realizadas en el LEMIT sobre la reacción que se produce entre el cemento y los agregados, en el hormigón de cemento Portland. Revista LEMIT Serie II 85:43 (Argentina, in Spanish)

4. Ponce JM, Batic OR (2006) Different manifestations of the alkali-silica reaction in concrete according to the reaction kinetics of the reactive aggregate. Cem Concr Res 36:1148-1156

5. Heisig A, Urbonas L, Beddoe RE, Heinz D (2016) Ingress of $\mathrm{NaCl}$ in concrete with alkali reactive aggregate: effect on silicon solubility. Mater Struct 49:4291-4303

6. Yuksel C, Mardani-Aghabaglou A, Beglarigale A, Yazıcı H, Ramyar K, Andic-Cakır O (2016) Influence of water/powder ratio and powder type on alkali-silica reactivity and transport properties of self-consolidating concrete. Mater Struct 49:289-299

7. Zapala-Sławeta J (2017) The effect of meta-halloysite on alkali-aggregate reaction in concrete. Mater Struct 50:217

8. Feiteira J, Custódio J, Sousa Ribeiro MS (2013) Review and discussion of polymer action on alkali-silica reaction. Mater Struct 46:1415-1427

9. Lesnicki KJ, Kim J-Y, Kurtis KE, Jacobs LJ (2013) Assessment of alkali-silica reaction damage through quantification of concrete nonlinearity. Mater Struct 46:497-509

10. Ju TH, Achenbach JD, Jacobs LJ, Guimaraes M, Qu JM (2017) Ultrasonic nondestructive evaluation of alkali-silica reaction damage in concrete prism samples. Mater Struct 50(1):60

11. Ling TC, Balachandran C, Munoz JF, Youtcheff J (2018) Chemical evolution of alkali-silicate reaction (ASR) products: a Raman spectroscopic investigation. Mater Struct $51: 23$

12. Rivard P, Saint-Pierre F (2009) Assessing alkali-silica reaction damage to concrete with non-destructive methods: from the lab to the field. Constr Build Mater 23:902-909

13. Saint-Pierre F, Rivard P, Ballivy G (2007) Measurement of alkali-silica reaction progression by ultrasonic waves attenuation. Cem Concr Res 37:948-956

14. Berra M, Costa U, Mangialardi T, Paolini AE (2015) Application of an innovative methodology to assessing the alkali-silica reaction in concrete. Mater Struct 48:2727-2740

15. Multon S, Sellier A (2016) Multi-scale analysis of alkalisilica reaction (ASR): impact of alkali leaching on scale effects affecting expansion tests. Cem Concr Res 81:122-133

16. Wallau W, Pirskawetz S, Voland K, Meng B (2018) Continuous expansion measurement in accelerated concrete prism testing for verifying ASR-expansion models. Mater Struct 51:79
17. Pleau R, Bérubé MA, Pigeon M, Fournier B, Raphaël S (1989) Mechanical behaviour of concrete affected by ASR. In: Proceedings of 8th international conference on alkaliaggregate reaction in concrete, Kyoto, Japan, pp 721-726

18. Giaccio G, Zerbino R, Ponce JM, Batic OR (2008) Mechanical behavior of concretes damaged by alkali-silica reaction. Cem Concr Res 38:993-1004

19. Gautam BP, Panesar DK (2016) A new method of applying long-term multiaxial stresses in concrete specimens undergoing ASR, and their triaxial expansions. Mater Struct 49:3495-3508

20. Islam MS, Ghafoori N (2015) Relation of ASR-induced expansion and compressive strength of concrete. Mater Struct 48:4055-4066

21. Doran DK, More JFA (1989) Appraisal of the structural effects of alkali-silica reaction. In: Proceedings of 8th international conference on alkali-aggregate reaction in concrete, Kyoto, Japan, pp 677-682

22. Swamy RN, Al-Asali MM (1988) Engineering properties of concrete affected by alkali-silica reaction. ACI Mater J 85:367-374

23. Smaoui N, Bérubé MA, Fournier B, Bissonnette B (2004) Stresses induced by ASR in reinforced concrete incorporating various aggregates. In: Proceedings of 12th international conference on alkali-aggregate reaction in concrete, Beijing, China, pp 1191-1201

24. Qian C, Guo H, Wang J, Yan A (1996) Influence of alkaliaggregate reaction on flexural properties of steel fibre reinforced concrete. In: Proceedings of 10th international conference on alkali-aggregate reaction in concrete, Melbourne, Australia, pp 474-481

25. Haddad RH, Smadi MM (2004) Role of fibres in controlling unrestrained expansion and arresting cracking in Portland cement concrete undergoing alkali-silica reaction. Cem Concr Res 34(1):103-108

26. Pires de Carvalho MR, de Moraes Rego Fairbairn E, Dias Toledo Filho R, Chagas Cordeiro G, Hasparyk NP (2010) Influence of steel fibres on the development of alkali-aggregate reaction. Cem Concr Res 40(4):598-604

27. Lindgard J, Andiç-Çakır O, Fernandesc I, Rønning TF, Thomas MDA (2012) Alkali-silica reactions (ASR): literature review on parameters influencing laboratory performance testing. Cem Concr Res 42(2):223-243

28. Giaccio G, Bossio ME, Torrijos MC, Zerbino R (2015) Contribution of fibre reinforcement in concrete affected by alkali-silica reaction. Cem Concr Res 67:310-317

29. ASTM Standards C1293 (2005) Standard test method for concrete aggregates by determination of length change of concrete due to alkali-silica reaction. ASTM International, West Conshohocken

30. ASTM Standards C1260 (2007) Standard test method for potential alkali reactivity of aggregates (Mortar-Bar method). ASTM International, West Conshohocken

31. Lindgard J, Thomas MDA, Sellevold EJ, Pedersen B, Andic-Cakır O, Justnes H, Rønning TF (2013) Alkali-silica reaction (ASR) - performance testing: influence of specimen pre-treatment, exposure conditions and prism size on alkali leaching and prism expansion. Cem Concr Res 53:68-90

32. Borchers I, Müller C (2014) 7 years of field site tests to assess the reliability of different laboratory test methods for 
evaluating the alkali-reactivity potential of aggregates. In: Proceedings of 14th international conference on alkali-aggregate reaction in concrete, Texas, USA

33. Ideker JH, Drimalas T, Bentivegna AF, Folliard KJ, Fournier B, Thomas MDA, Hooton RD, Rogers CA (2014) The importance of outdoor exposure site testing. In: Proceedings of 14th international conference on alkali-aggregate reaction in concrete, Texas, USA

34. Wigum BJ, Einarsson GJ (2016) Alkali aggregate reaction in Iceland-results from laboratory testing compared to field exposure site. In: Proceedings of 15 th international conference on alkali-aggregate reaction in concrete, São Paulo, Brazil

35. Fournier B, Nkinamubanzi PC, Lu D, Thomas MDA, Follard KJ, Ideker JH (2006) Evaluating potential alkali-reactivity of concrete aggregates-how reliable are the current and new test methods?. In: Proceedings of MA Bérubé symposim on alkali-aggregate reactivity in concrete, Montréal, Canada, pp 21-44

36. Hooton RD, Rogers C, MacDonald CA, Ramlochan T (2013) Twenty-year field evaluation of alkali-silica reaction mitigation. ACI Mater J 110(5):539-548

37. Lindgard J, Sellevold EJ, Thomas MDA, Pedersen B, Justnes H, Rønning TF (2013) Performance testing: Influence of specimen pre-treatment, exposure conditions and prism size on concrete porosity, moisture state and transport properties. Cem Concr Res 53:145-167

38. IRAM 1700 (2013) Aggregates. Method for the determination of length change in concrete prisms due to alkaliaggregate reaction (in Spanish)

39. EN 14651:2005 Test method for metallic fibered concretemeasuring the flexural tensile strength (limit of proportionality (LOP), residual). CEN-European Committee for Standardization, Brussels, pp 1-17

40. Torrent R (1992) A two chamber vacuum cell for measuring the coefficient of air permeability of the concrete cover on site. Mater Struct 25:358-365

41. Romer M (2005) Recommendation of RILEM TC 189-NEC: 'Non-destructive evaluation of the concrete cover' comparative test-Part I-comparative test of penetrability' methods. Mater Struct 38:895-906

42. Jones EK, Clark LA (1996) The effects of restraint on ASR expansion of reinforced concrete. Mag Conc Res 48(174):1-13

43. Multon S, Barin FX, Godart B, Toutlemonde F (2008) Estimation of the residual expansion of concrete affected by alkali silica reaction. J Mater Civ Eng 20(1):54-62

44. Larive C, Laplaud A, Coussy O (2000) The role of water in Alkali-Silica Reaction. In: Proceedings of 11th international conference on AAR, Quebec, Canada, pp 61-70
45. Larive C, Joly M, Coussy O (2000) Heterogeneity and anisotropy in ASR-affected concrete-consequences for structural assessment. In: Proceedings of 11th international conference AAR, Quebec, Canada, pp 919-928

46. ASTM C 1778-16 (2016) Standard guide for reducing the risk of deleterious alkali-aggregate reaction in concrete. ASTM International, West Conshohocken

47. Gao X, Multon S, Cyr M, Sellier A (2011) Optimising an expansion test for the assessment of alkali-silica reaction in concrete structures. Mater Struct 44:1641-1653

48. Lindgård J (2013) Alkali-silica reactions (ASR)—performance testing. Ph.D. thesis, Norwegian University of Science and Technology Trondheim

49. Wigum BJ, Einarsson GJ (2016) Alkali aggregate reactions in Iceland. Results from laboratory testing compared to field exposure. In: Proceedings of 15th international conference on alkali-aggregate reaction in concrete, São Paulo, Brazil

50. Pedersen BM, Wigum BJ, Lindgård J (2016) Influence of aggregate particle size on the alkali silica reaction-a literature review. In: Proceedings of 15 th international conference on alkali-aggregate reaction in concrete, São Paulo, Brazil

51. Smaoui N, Bissonnette B, Bérubé MA, Fournier B (2007) Stresses induced by alkali-silica reactivity in prototypes of reinforced concrete columns incorporating various types of reactive aggregates. Can J Civ Eng 34:1554-1566

52. Multon S, Seignol JF, Toutlemonde F (2005) Structural behavior of concrete beams affected by ASR. ACI Mater J 102(2):67-76

53. Giaccio G, Torrijos MC, Tobes JM, Batic OR, Zerbino R (2009) Development of alkali-silica reaction under compressive loading and its effects on concrete behaviour. ACI Mat J 106(3):223-230

54. Wald D, Martínez GA, Bayrak O (2017) Expansion behaviour of a biaxially reinforced concrete member affected by ASR. Struct Conc 18:550-560

55. Wald DM, Allford MT, Bayrak O, Hrynyk TD (2017) Development and multiaxial distribution of expansions in reinforced concrete elements affected by alkali-silica reaction. Struct Conc 18:914-928

56. Bossio ME, Torrijos MC, Zerbino R, Giaccio G (2012) Pull out behaviour of macro synthetic fibres: effects of fibre type, matrix strength and microcracking. In: Proceedings of Bond in concrete 2012: Bond, anchorage, Detailing, fourth international symposium, Brescia, Italy, vol 2. Bond in new materials and under severe conditions, pp 901-906

Publisher's Note Springer Nature remains neutral with regard to jurisdictional claims in published maps and institutional affiliations. 